\title{
GIS MODEL OF THE BASIC GEOLOGICAL MAP AS A BASIS FOR GEODATABASE OF THE REPUBLIC OF MACEDONIA
}

\author{
M.Sc. Blagoj Delipetrev ${ }^{1}$, Prof. Dr. Todor Delipetrov ${ }^{2}$, M.Sc. Blagica Doneva ${ }^{3}$, Eng. \\ Dejan Boskovski ${ }^{4}$ \\ 1,2,3 University "Goce Delcev", ${ }^{1}$ Faculty of Computer Science, ${ }^{2,3}$ Faculty of Natural Sciences \\ and Technology, Republic of Macedonia.
}

\begin{abstract}
${ }^{4}$ AD MEPSO (Electricity Transmission System Operator of Macedonia), Republic of Macedonia.
\end{abstract}

\begin{abstract}
This paper presents the process of digitalization of the Basic Geological Map with scale 1:200 000 of the Republic of Macedonia in software package Maplnfo professional 8.0 as a basis for preparing geodatabase for the Republic of Macedonia. The procedure of design and implementation of a GIS project for the Basic Geological Map of the Republic of Macedonia is given, starting with the design of the database table, selecting attributes and entering vector graphical objects. Model of geodatabase is developed using latest information technologies, GIS and integrated database, allowing further development and upgrade. A list of digital data and maps that are included in the geodatabase is shown, together with the logical structure for entering data into the geodatabase and the service architecture of applications and data redundancy.
\end{abstract}

Key words: GIS, geodatabase, geological map, digitalization, vectorization

\section{INTRODUCTION}

A geologic map is the principal tool that geologists use to convey information about the structure and stratigraphy of the earth's surface, the location and type of geologic hazards and earth resources. The most powerful and useful aspect of geological maps (especially large-scale) is the correct representation of rocks with added information of time. A geological map is thus an information system on a horizontal reference plane, which is crucial in understanding not only where earth resources and characteristics are located, but also how and when these earth features were formed.

The primary objective of geological map is to reconstruct the geological evolution of the area. A geologist understands the geometries of the rock bodies and their lateral and vertical relationships from the map. Idea about the three - dimensional nature of the rocks and their relative ages is obtained from this information which in turn helps in interpreting the geological history of the area. Having acquired this knowledge, the geologist can then apply his understanding in solving problems related to earth resources, hazard assessment, and land-use planning. Basic Geological Map of the Republic of Macedonia was produced when the Republic of Macedonia was part of Former Yugoslavia. It was made and printed by the Department of Cartography "Geokarta", Belgrade 1977. Investor was the Research Council in Mining, Skopje 1977. 
Basic Geological Map (BGM) was compiled in 1975 and is not in digital form. If we want to use this map more efficiently, we must digitalize the map. Geological maps are extremely complex documents with many different types of information displayed. So, we must be careful when we process this map through GIS [1] software.

With the use of information technology and digital geological maps, there are new opportunities for in-depth analysis of various aspects, quick access to information, more reliable information, efficient work etc [2]. Using and transfer digital map is far more efficient than the classical paper map.

Based on the experience from the developed countries [3] [4] (Canada, USA and Netherlands) Republic of Macedonia needs to develop its own geodatabase. Centralized geodatabase will allow efficient management of mineral resources, urban planning, ecology and many other sectors. Geodatabase will be central point where ministries, private companies, faculties and others will search and access geosciences data and information. Geodatabase will enable government institutions to be more efficient in controlling and managing geo-resources. Data from the geodatabase will be available to citizens and companies and improve further investigations and investments in the country.

Importance and cost benefit analysis of developing the geodatabase is confirmed with Dutch studies. Dutch experience shows that the annual government investment in geoscientific information is $0.1 \%$ of the value of the managed data \& information resources. In present situation every government institution (ministry, university, government agencies) are doing their own geo-data processing. Without centralized state geo-data repository access of the data is difficult for institutions and users.

Digitalization of the paper data is necessary. For paper data acquisition are spent enormous resources in funds, time and people. Archiving paper data in digital form should be priority for the government.

\section{MOTIVATION AND RELATED WORK}

In 1988 a tectonic map 1:200 000 of the Republic of Macedonia was digitized. Publisher was the Faculty of Mining and Geology in Stip, Department of Geology and Geophysics. Software package Maplnfo professional 3.0 was used for digitalization of the tectonic map. In addition to tectonic layers, there are layers of roads, boundaries, town etc. Using the experience of compiling a tectonic map it was decided that software package Maplnfo professional 8.0 [5] is used for digitalizing BGM of the Republic of Macedonia. In that manner a comparison and use of previous work of the tectonic map and new digital BGM can be done. Analysis of the two maps will give in depth presentation of the geological and tectonic area in the Republic of Macedonia.

In the past years a team from the Faculty of Natural and Technical sciences worked on digitalization of paper maps and data [6]. The goal is to include digital data into the geodata repository system [7]. Parallel with the digitalization, strategy was building which data and maps should be processed. Digitalization of the maps is done with its scanning and their vectorization. Digital data is stored so latter can be included in the geodatabase. In the past period the team worked on vectorization of the basic geological map 1:200 000, hydro-geological map 1:200 000, other maps and data. 


\section{SCANNING AND REGISTRATION OF THE BASIC GEOLOGICAL MAP OF THE REPUBLIC OF MACEDONIA}

First step in digitalization is scanning of the map. BGM 1:200 000 of the Republic of Macedonia is divided in 23 pieces of A4 format and scanned with HP Scan jet 9100. Process of scanning is important for lowering error of deformation of the map. Scanned map images have at least 4 coordinate points (longitude, latitude).

After scanning of the map, result is digitized raster map. Next step in the process is registration of the map. Registration of the raster map BGM in MapInfo is done with referencing 4 coordinate points. Error in the process of the registration of BGM in MapInfo is arround 2-3 pixels and in the worst case 4 pixels.

\section{BASIC GEOLOGICAL MAP LAYERS}

Important step in vectorization process is defining the map layers. The process starts with analyzing the information shown on the map. GIS software store maps geographic information in layers. Typically every layer is made of a geographical vector or raster object and table (table of data). Most common vector objects are point, polyline or region. Every object from the map is connected with a row in the table. Table columns are attributes that define geographical object.

In the process of analyzing the BGM are defined 4 layers. Layers are closely related to the map legend. The first layer defines geological regions. Geological region is defined with its color, pattern and label. Attributes of the geological region are given in table 1.

Table 1. Attributes of the layer geological regions

\begin{tabular}{|l|l|l|l|l|}
\hline Geoind & Symbol & Period & Era & Opis_na_karpa \\
\hline Integer & Char -15 & Char -50 & Char -30 & Char -150 \\
\hline
\end{tabular}

Geoind is integer number which is used as index. Symbol is the geological label of the region. Period defines when the geological region is made. Era defines geological epoch. Opis_na_Karpa is the legend of the rocks.

Second layer are the borders between the geological region and part of structure formation from the geological map. Every object is polyline that is defined with line style. Table of attributes of the border layer is given in table 2 .

Table 2. Attributes of the layer borders

\begin{tabular}{|l|l|}
\hline GranicaInt & TipGranica \\
\hline Integer & Integer \\
\hline
\end{tabular}

Attribute TipGranica is integer number that correspond with the next listing: Normal border -1, Gradual transition-2, Erozive border-3, Intrusion of igneous body-4, Outflow of volcano-5, Elements of slope of layer-6.

Third layer is representing rest of the structure formations from the geological map. The attributes table is given in table 3. 
Table 3. Attributes of the layer structure formation

\begin{tabular}{|l|l|}
\hline RasedInt & Opis_R \\
\hline Integer & Integer \\
\hline
\end{tabular}

Attribute Opis_R get integer values 1-8 from the list that follows: Anticline axes-1, Funcline axes-2, Observed fault-3, Assumed fault-4, Determined overthrust-5, Assumed overthurst-6, Diapir contact-7, Tectonic clip-8.

The last is the label layer. MapInfo option of automatic labeling doesn't give good results. So it was necessary to make a separate layer for the labels.

After layers are defined, starts the process of vectorizing the raster BGM map. Vectorization is a process of drawing vector objects on top of the raster map. A vector object is defined with its geographical coordinates, color and pattern and row in the attribute table.

\section{VECTORIZED BASIC GEOLOGICAL MAP}

Vectorized BGM 1:200 000 of the Republic of Macedonia is shown on figure 1. The map contains all previous vectorized layers. Vectorized BGM is vectorized digital copy of the paper map.

Figure 1. Vectorized Basic Geological Map 1:200 000 of the Republic of Macedonia
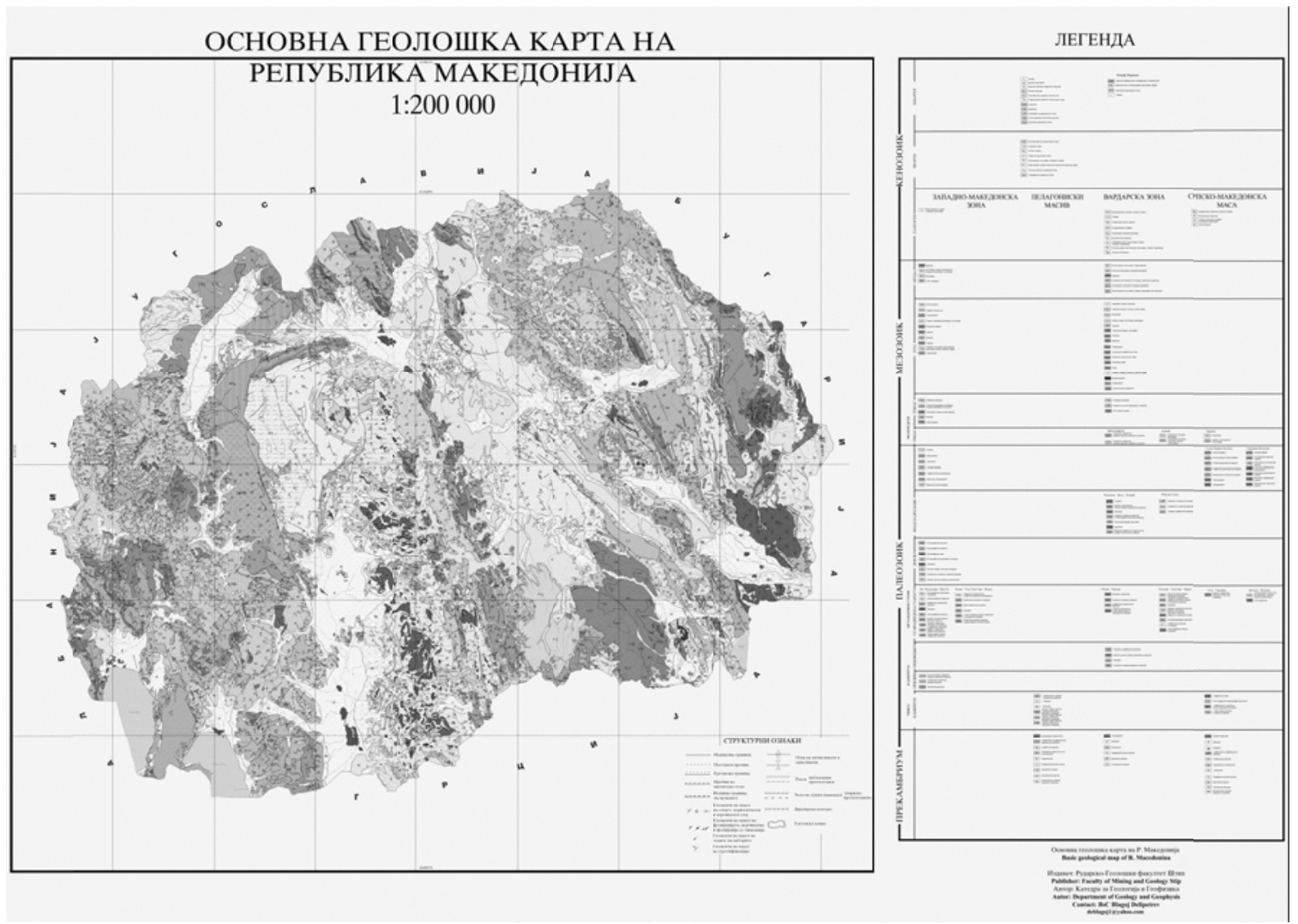
Maximum error in the process of registration of the map is 4 pixels. In the process of tiling two parts of the map error in connecting points was between 7 and 120 meter. Map resolution is $1: 200000$ which means that $1 \mathrm{~mm}: 200000 \mathrm{~mm}=200 \mathrm{~m}$ and connecting point error is very small. Vectorized map is compared with previous developed maps and Google maps and conclusion is that accuracy of the vectorized BGM is excellent.

Possibilities for processing the data from vectorized map are enormous. Layers can be analyzed by some attribute, selecting objects by their characteristic, using SQL queries in the attribute table etc. The BGM can be used as a basic for geodatabase of the Republic of Macedonia.

\section{MODEL OF THE GEODATABASE OF THE REPUBLIC OF MACEDONIA}

Model of the geodatabase of the Republic of Macedonia is build using gained knowledge from the research in similar projects from developed countries. The geodatabase is based on the latest information technologies utilizing GIS and integrated database that will allow further development.

In the beginning of the research first task was to determine quantity of geo-data that should be included into the geodatabase. For this reason several experiments and investigations were done. Research has shown that Basic Geological Map 1:200 000 can be used as foundation of the geodatabase. Scale 1:200 000 was selected because it holds most relevant data for the territory. In the maps with higher scale relevant data is absent; on the other hand smaller scale maps are overloaded with data. This map holds relevant data for the territory of the Republic of Macedonia and can be included in many applications in the field of geology. Time needed to vectorize this map is less than maps with smaller scale. Bellow is given a list of maps that are included into the geodatabase:

1. Location data (roads, rivers, springs, lakes, etc.),

2. Basic geological map 1:200000,

3. Tectonic map 1:200 000,

4. Hydrogeology map 1:200 000,

5. Scan of the basic geological map 1:100 000, together with paper data,

6. Geophysics,

7. Geochemical map,

8. Physical-mechanical and chemical laboratory data,

9. Data of geological explorations of the Republic of Macedonia,

10. Map of concessions,

11. Database of reports,

12. Other type of data.

All the maps/data have their properties that are considered before including in the geodatabase. That's why there is a need to form a team of experts from geology, geophysics, geodesy, IT that will define data and attributes. Maps and data will be grouped in databases that together will form central geodatabase repository. 


\section{LOGICAL AND SERVICE ARCHITECTURE OF THE GEODATABASE}

Logical scheme of the geodatabase of the Republic of Macedonia is presented on figure 2. Figure 2 shows the data flow of information. First step is digitalization of paper data. These phase start with scanning paper maps, vectorization of scanned maps, entering data, etc. After maps and data digitalization is done next is to complete the quality control. When processed data pass quality control is included into the geodatabase. Data entered into geodatabase is archived and grouped by type.

Figure 2. Logical scheme of the geodatabase

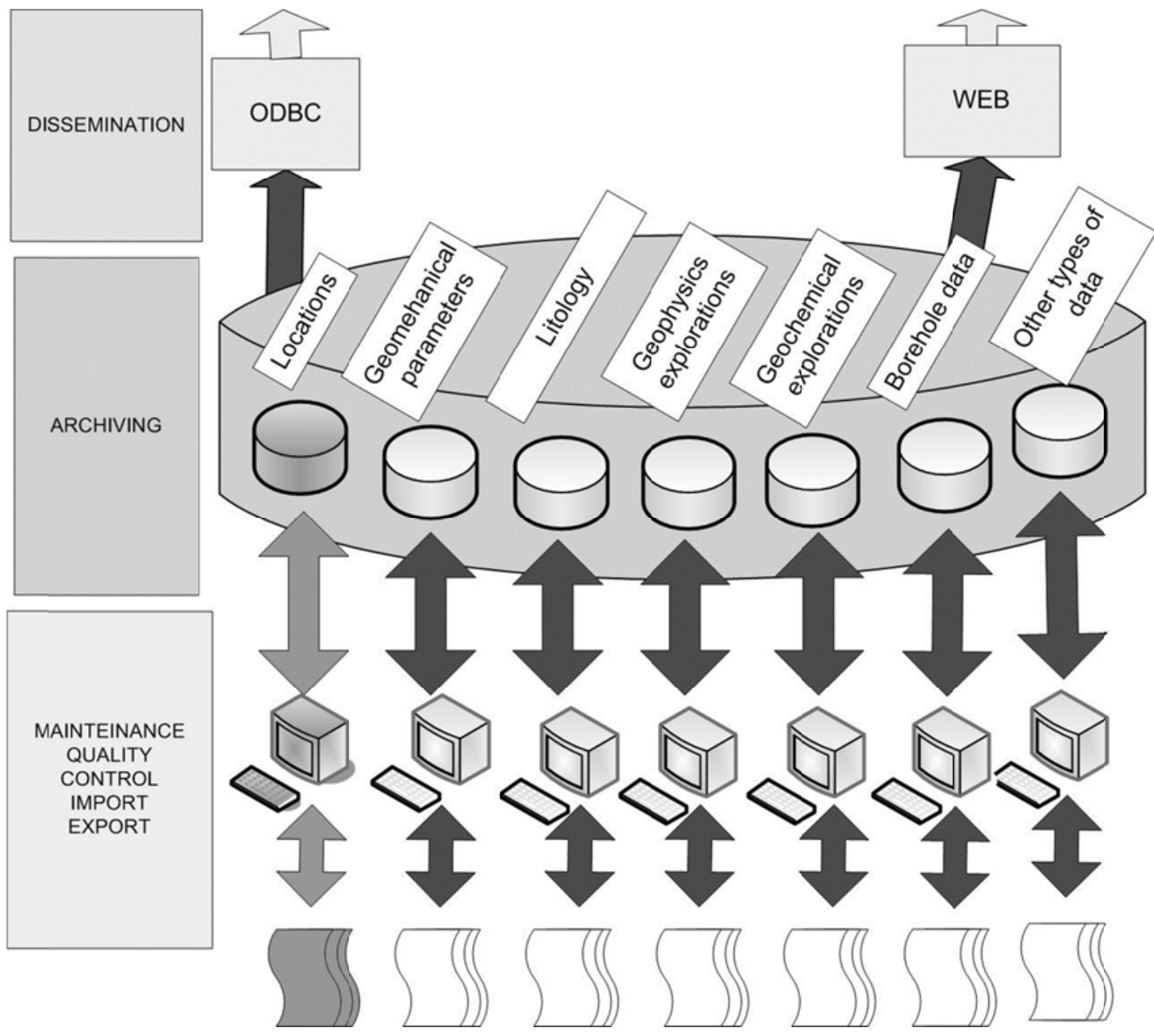

Model of geodatabase consist of several geodatabases for different type of data figure 3 . This allows distributed architecture of the centralized geodatabase and fragmentation in more independent databases that could be easily management. Independent databases can be redundant with central geodatabase. This architecture will provide higher protection of the geodatabase data. 
Figure 3. Distributed geodatabase architecture

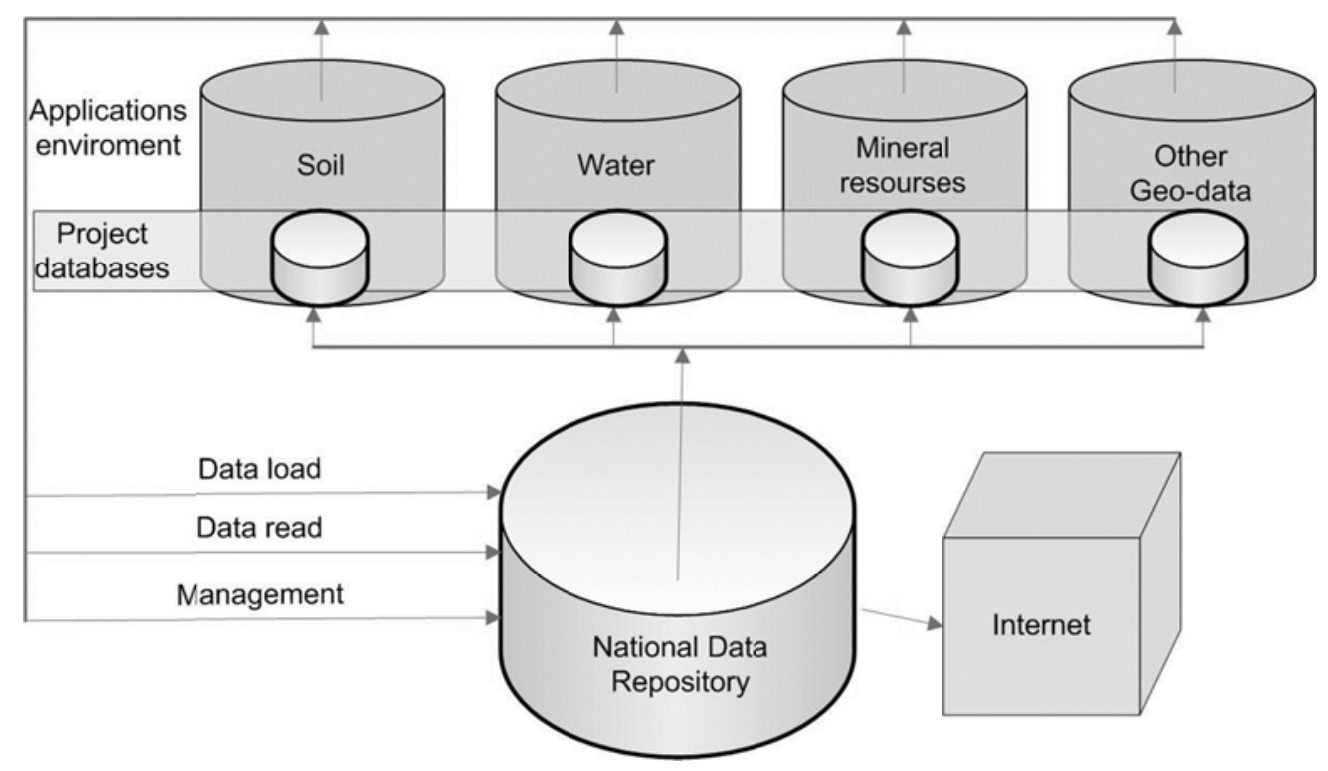

Geodatabase service architecture is consisting of three layers given on figure 4 . The first layer is data storage layer that stores data into relational database. There are also defined metadata for efficiency searching of the database. The second layer is a service application which enables communication between users and geodatabase. In this layer services and their capabilities are defined. User layer holds applications that access the geodatabase. Geodatabase provides access over browser, GIS programs, Maplnfo and others.

Figure 4. Geodatabase service architecture

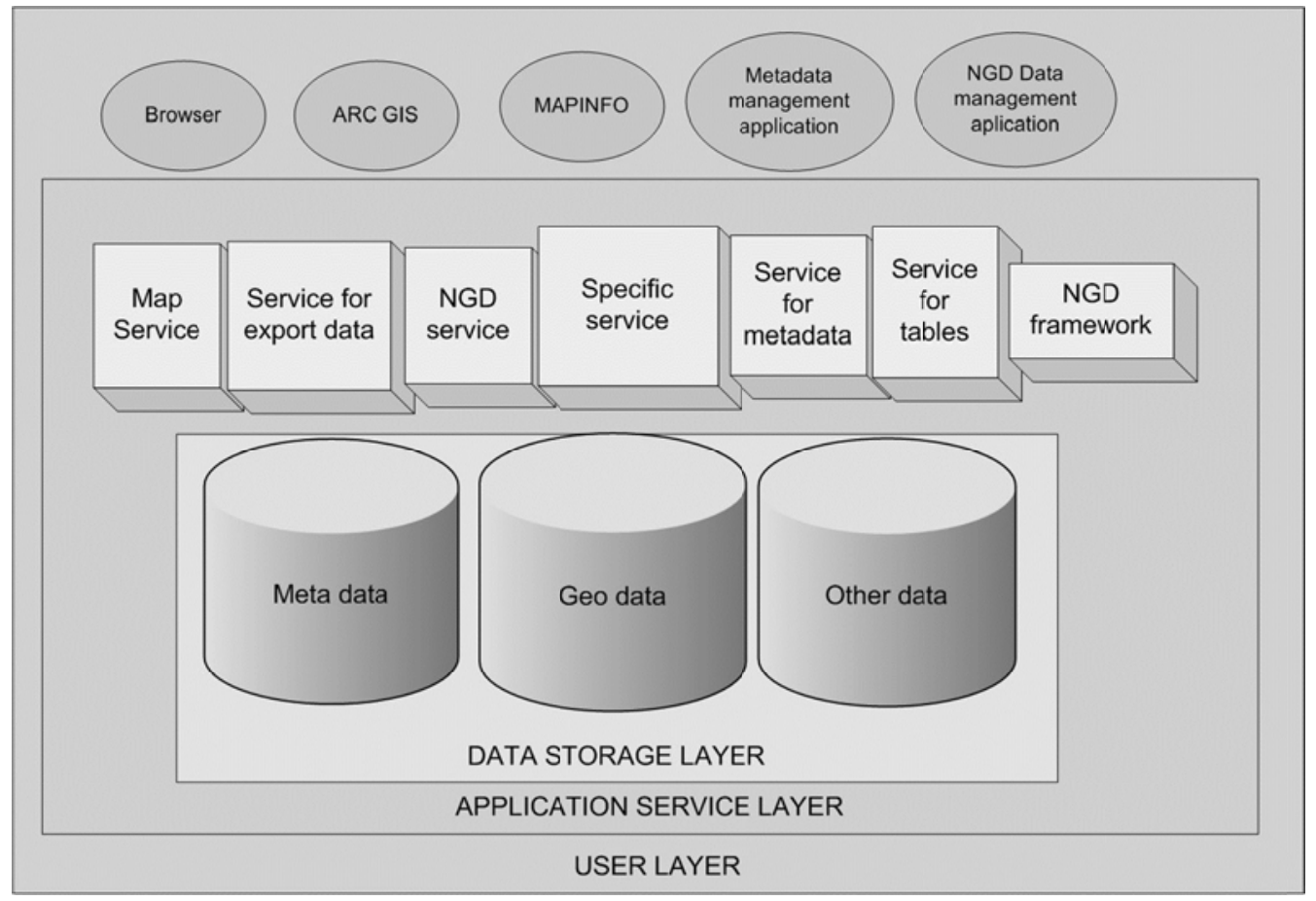




\section{CONCLUSION}

This paper shows the procedure of digitalization and vectrorization of the Basic Gelogical Map 1:200 000 and basic model of the geodatabase of the Republic of Macedonia. Basic Geological Map is vectorized using GIS software MapInfo. All phases of digitalization are described starting with scanning of the map, defining the map layers, vectorization, filling table data and combining all layers into the final map. Research and development of the geodatabase is presented using latest information technology, GIS, web services and other. Presented model is original and it's based on experiences of developed countries having in mind existing Macedonian maps and data. Implementation of the model is presented in the master's work "Model of the geodatabase of the Republic of Macedonia". List of maps that are included into the geodatabase together with the architecture, logical design and its real implementation is explained. For completion and building the geodatabase government support is necessary.

\section{REFERENCES}

1. DeMers, M.N., Fundamentals of geographic information systems. 2008: WileyIndia.

2. Kretschmer, U. and E. Roccatagliata. CommonGIS: a European project for an easy access to geo-data.

3. Brodeur, J., Y. Bédard, and M.J. Proulx. Modelling geospatial application databases using UML-based repositories aligned with international standards in geomatics. 2000: ACM.

4. Lance, K., SDI evaluation and budgeting processes: linkages and lessons. A Multi-View Framework to Assess SDIs, 2008: p. 69.

5. MapInfo, MapInfo Professional Version 7.0. 2002, MapInfo Corporation.

6. Delipetrov, B., et al., Digital model of the Basic Geological Map of the Republic of Macedonia. 2005.

7. Delipetrov, B., D. Mihajlov, and M. Delipetrov. Geo-database model of the Republic of Macedonia: IEEE. 